\title{
Motivação competitiva de "squashistas" juvenis federados
}

CDD. 20.ed. 796.011

796.34

http://dx.doi.org/10.1590/1807-55092014000300469

\author{
Fernando Machado CECHIN* \\ Paulo Henrique Mellender EVANGELISTA* \\ Ricardo Pedrozo SALDANHA ${ }^{* * * * * * *}$ \\ Marcos Alencar Abaide BALBINOTTI ${ }^{* * * *}$ \\ Roberto Tierling KLERING* \\ Marcus Levi Lopes BARBOSA $A^{* * * * *}$ \\ Carlos Adelar Abaide BALBINOTTI*
}

*Escola de Educação Física, Universidade Federal do Rio Grande do Sul.

${ }^{* *}$ Centro Universitário La Salle.

${ }^{* * *}$ Faculdade Cenecista de Osório. ****Université du Québec à Trois-Rivières - Quèbec - Canada. $* * * *$ Universidade

FEEVALE.

\section{Resumo}

A Motivação Competitiva (MC) é uma característica de personalidade fundamental no contexto dos esportes. Recentemente foi proposto um modelo de avaliação da MC chamado Modelo Tridimensional de Avaliação da Motivação Competitiva (MTAMC). Esse modelo supõe que a MC possui três orientações competitivas distintas: Orientação à Vitória (OV), Orientação à Performance (OP) e Orientação ao Status (OS). 0 objetivo da presente pesquisa foi explorar e comparar o perfil motivacional competitivo de 35 "squashistas" juvenis federados, de ambos os sexos e com idades entre 13 e 18 anos. Para tanto, essa amostra respondeu a Escala Balbinotti de Motivos à Competividade no Esporte (EBMCE-18). Os dois principais resultados foram: 1) as orientações foram OP, OV e OS, nessa ordem, sendo que OP e OV é o único dos três pares analisados que não se diferencia estatisticamente; 2) a variável sexo não influenciou a intensidade das respostas em qualquer das três orientações testadas. Novos estudos devem explorar se na diferença não significativa encontrada entre OP e OV houve a influência do tamanho da amostra.

Palavras-chave: Competitividade; "Squash"; Motivação; Psicometria.

\section{Introdução}

A Motivação Competitiva (MC) é uma característica de personalidade fundamental no contexto dos esportes, e no caso do "Squash" essa realidade não é diferente. Estudos atuais ${ }^{1-4}$ destacam a motivação competitiva, ou simplesmente competitividade, como uma das seis fundamentais dimensóes motivacionais (Controle de Estresse, Saúde, Sociabilidade, Competitividade, Estética e Prazer) para a prática regular de atividades esportivas. Segundo BALBINOTTi e BALBinotTí ${ }^{5}$, a Competitividade é a dimensão que mais motiva os atletas infanto-juvenis, inclusive podendo estar associada às aspirações profissionais desses atletas. Entretanto, não se tem conhecimento de possíveis publicações onde tenham sido exploradas as orientaçôes intrínsecas da motivação competitiva, possivelmente por se tratar de um modelo publicado muito recentemente (Modelo Tridimensional de Avaliação da Motivação Competitiva) por BALBINotTı et al. ${ }^{6}$ É com base nessas observaçôes, nas conclusóes que concernem à tridimensionalidade do construto competitividade ${ }^{6}$ e, ainda, na importante exclamaçáo de Marques e Oliveira ${ }^{7}$ - não há esporte sem competiçâo! - que se justifica a importância desse estudo.

O presente estudo visa explorar o perfil motivacional competitivo de atletas brasileiros de 13 a 18 anos, mais especificamente o objetivo consistiu em investigar as três orientaçôes competitivas (Orientação à Vitória, Orientação à Performance e Orientação ao Status) de atletas de squash de clubes do Sul do Brasil.

Para que se possa responder adequadamente ao objetivo serão apresentadas, as estruturas gerais do "squash" e aspectos teóricos e empíricos relacionados ao constructo da competitividade.

\section{Estruturas gerais do "squash"}

O "Squash" pode ser classificado como um esporte de raquete ou "de parede". Não há oposição direta 
entre os jogadores ${ }^{8-10}$. A quadra é fechada por quadro paredes e todas podem ser utilizadas, porém a parede frontal é a referência principal para a execução das jogadas ${ }^{8,11}$. Considerando o espaço relativamente restrito $\left(70 \mathrm{~m}^{2}\right.$ individual ou $80 \mathrm{~m}^{2}$ duplas) ocupado pelos jogadores e a velocidade que devem se movimentar ${ }^{12}$ para obter o ponto ${ }^{13}$, pode-se inferir que a velocidade é uma das características fundamentais desse esporte; não esquecendo, obviamente, da alta exigência de habilidades técnicas que podem ser percebidas na execução alternada de ações táticas e tomadas rápidas de decisão ${ }^{14}$, pois estas também são características típicas dessa modalidade esportiva. Devido ao fato desse esporte "exigir" tais características (e mesmo outras), não é difícil imaginar que os atletas podem se motivar pela competição consigo mesmo (melhorar a própria performance), com o oponente (obter a vitória) e, ainda, obter reconhecimento social (ser reconhecido no meio social). E são precisamente esses aspectos que caracterizam a motivação competitiva ${ }^{6}$.

\section{Aspectos teóricos relacionados à motivação competitiva}

No plano teórico, a motivação competitiva tem sido entendida como uma das características de personalidade típica de atletas, podendo ser claramente observada em situaçóes de competiçóes. Segundo Weinberg e Gould ${ }^{15}$, essa característica pode, inclusive, se referir à satisfação em competir e, até mesmo, o desejo de lutar pelo sucesso nas competiçóes que esses atletas participam. Sendo assim, para esses mesmos autores, a motivação competitiva, ou simplesmente competitividade, pode ser orientada à vitória ou orientada a um determinado objetivo (sem, necessariamente, incluir a vitória nesse objetivo). Por um lado, as pessoas com orientaçáo dirigida à vitória possuem um foco motivacional competitivo dirigido à comparação interpessoal, querem ser os melhor, vencer a todos. Por outro lado, as pessoas com orientaçáo a um determinado objetivo possuem um foco motivacional dirigido a padróes de desempenho pessoal, querem melhorar as suas marcas, melhorar suas habilidades ${ }^{15}$. Segundo BalbinotTi et al. ${ }^{2}$ é precisamente o nível dessas orientaçôes que deve afetar a forma como o atleta percebe a situação competitiva. Portanto, parece essencial explorar em profundidade essas orientaçóes, e foi exatamente esse o recente trabalho realizado por BALBINOTTI et al. ${ }^{6}$.

Com base nas reflexôes de DASSA ${ }^{16}$, quando afirma que muitas das variáveis que integram a personalidade humana são construtos multidimensionais, e de De Rose Junior e Korsakas ${ }^{17}$, que entendem que o construto competitividade deve ser avaliado considerando determinados aspectos precisos (confronto, disputa, resultado, avaliação, seleção, vitória, derrota, pressão, alegria e frustração), BALBINOTTI ${ }^{18}$ elaborou um novo instrumento de avaliação da motivação competitiva, denominado Escala Balbinotti de Motivos à Competitividade no Esporte (EBMCE-18). Esse instrumento avalia, precisamente, três diferentes perspectivas gerais da competitividade: 1) como uma forma de manifestação de aspectos (positivos e negativos) relacionados a vitórias e derrotas; 2) com uma forma de busca do desenvolvimento e melhoria da performace pessoal; e, 3) como uma forma de obtençáo de reconhecimento social, a partir do sucesso obtido nas disputas esportivas em geral ou no desenvolvimento da performance esportiva ${ }^{6}$. Sendo assim, e conforme os resultados desses autores, a proposição bidimensional das orientaçóes à competitividade proposta por WeInBERG e Gould ${ }^{15}$ foi ampliada para três orientaçóes relacionadas, mas com construtos independentes: Orientaçáo à Vitória $(\mathrm{OV})$, Orientação à Performance $(\mathrm{OP})$ e Orientação ao Status (OS) (ver QUADRO 1). Portanto, ao se classificar um atleta como "competitivo", deve-se, conforme as conclusóes de BalbinotTi et al. ${ }^{6}$, ter que especificar o perfil das orientaçóes desse atleta, pois, como já mencionado, é precisamente o nível dessas orientaçóes que deve afetar a forma como o atleta se comporta em situaçóes competitivas ${ }^{2}$, interferindo, inclusive, no modelo de treinamento. 
QUADRO 1 -Ilustrativo do modelo conceitual e de avaliação tridimensional da motivação competitiva.

\begin{tabular}{|c|c|c|}
\hline & Orientação & Características \\
\hline \multirow[t]{3}{*}{$\begin{array}{l}\text { Motivação } \\
\text { Competitiva }\end{array}$} & Vitória & $\begin{array}{l}\text { Avalia em que nível as pessoas competem no esporte como forma de manifestação } \\
\text { de aspectos relacionados ao vencer }{ }^{2} \text {, considerando as comparaçóes interpessoais } \\
\text { e a superaçáo dos outros competidores como o foco desta orientação }{ }^{15} \text {, tendo } \\
\text { também em vista a projeçáo para a vitória ("aconteça o que acontecer"), como } \\
\text { objetivo de alcançar o máximo em termos individuais para superar os outros }{ }^{19} \text {. }\end{array}$ \\
\hline & Performance & $\begin{array}{l}\text { Avalia em que nível as pessoas competem no esporte como forma de manifestação } \\
\text { dos aspectos relacionados ao desenvolvimento das habilidades pessoais }{ }^{6} \text {, conside- } \\
\text { rando que os objetivos estão direcionados a superar os próprios limites }{ }^{20-21} \text { e são } \\
\text { representados de forma objetiva ou subjetiva, focalizando-se, fundamentalmente, } \\
\text { em padróes de desempenho pessoal }{ }^{15} \text {. }\end{array}$ \\
\hline & "Status" & 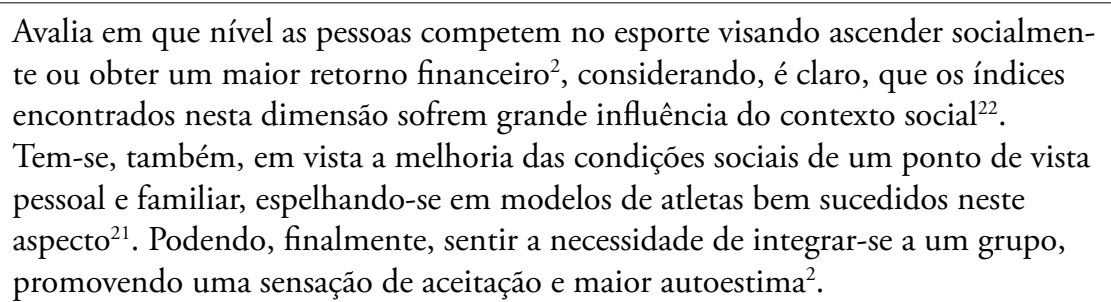 \\
\hline
\end{tabular}

\section{Aspectos empíricos relacionados à motivação competitiva segundo as variáveis "Sexo" e "Idade"}

No plano empírico, nota-se que o construto Motivação Competitiva (MC), ou simplesmente competitividade, tem sido testado sob o controle da variável "Sexo". Por exemplo, em um estudo publicado recentemente, BALBINOTTI et al. ${ }^{6}$ testaram a $\mathrm{MC}$ de um grupo de 635 adolescentes e adultos praticantes regulares de atividades físicas e esportivas e concluem que essa não se diferencia quando controlada a variável "Sexo". Esses autores afirmam que, na realidade, seria um tanto surpreendente se um dos sexos se mostrasse mais competitivo que o outro, unicamente por ser um atleta homem ou mulher. Mas, em seguida indicam que seria uma falácia imaginar que não pudessem existir diferenças significativas quando fossem propriamente investigadas as dimensóes constitutivas da MC, sugerindo ser um importante estudo a ser realizado.

Já BARBOSA ${ }^{23}$ e JuCHEM ${ }^{24}$ indicam que os jovens entre 13 e 14 anos apresentam índices de competitividade significativamente superiores em relação às suas companheiras de esporte. Conforme o estudo de JuCHEM ${ }^{24}$, com tenistas infanto-juvenis brasileiros, os índices médios de competitividade decrescem, independentemente do sexo, à medida que os tenistas avançam de categoria de idade. Deixando entender que, por um lado, o tipo de competitividade avaliado pelo IMPRAFE-126 (instrumento utilizado por esse autor), fundamentalmente orientada à vitória, é mais característico dos mais jovens; e, por outro lado, na medida em que as categorias de idade avançam, outro tipo de competitividade deveria ser explorado, possivelmente aquele orientado à performance. Destaca-se que resultados idênticos foram encontrados por BALBINOTTI et $\mathrm{al}^{2}{ }^{2}$, com uma amostra de basquetebolistas infanto-juvenis.

No caso de alunos (clientes) de academias, acompanhados por uma "personal training", BALBINOTTI e CAPOZZOLI ${ }^{25}$ indicaram que, efetivamente, existem diferenças estatisticamente significativas na motivação competitiva, quando controlada a variável "Sexo". Mesmo não sendo o tipo de motivação mais característico desses alunos, os autores interpretaram que a competitividade nesse contexto pode estar associada à força muscular, corroborando, inclusive, com as pesquisas de Cohane e Pope Junior ${ }^{26}$, e de Robertson e Mutrie ${ }^{27}$, quando esses afirmam que os alunos masculinos de academias buscam, fundamentalmente, a performance muscular e força física. LoREs et al. ${ }^{28}$, com uma amostra de universitários atletas, também concluiram que os índices de competitividade são significativamente mais elevados nos atletas masculinos que femininos, de acordo, portanto, com os resultados de BALBinotti e CAPOZZOLI ${ }^{25}$.

Infelizmente, não foram encontrados resultados publicados com a EBMCE-18 no contexto de esportes específicos (como no caso desse estudo) e, portanto, em nenhum desses estudos supracitados, foram exploradas ou comparadas as médias das três 
orientaçôes intrínsecas (OV, OP e OS) à variável "competitividade"; acredita-se que seja pelo fato do modelo e do instrumento ainda serem considerados muito recentes.

\section{Questões centrais dessa pesquisa}

Considerando a importância desse traço de personalidade bem como a constataçáo de que a motivação competitiva não é de natureza unidimensional, o

\section{Método}

\section{Procedimentos}

O Comitê de Ética em Pesquisa da Universidade Federal do Rio Grande do Sul analisou e aprovou o projeto sob o número de referência 2007720. Inicialmente, foram contatados a Confederação Brasileira de Squash (CBS) e os responsáveis pelos adolescentes com o propósito de obter o TCLE (Termo de Consentimento Livre e Esclarecido), possibilitando a aplicação da "Escala Balbinotti de Motivos à Competitividade no Esporte (EBMCE-18)" nos atletas que se dispusessem. A seguir, e após a apresentaçáo formal dos objetivos da pesquisa aos atletas disponíveis, todos foram convidados a participar do estudo. Deixou-se claro que a participaçáo era livre, podendo o atleta desistir da participaçáo em qualquer momento, presente e futuro, se assim o desejasse. Para tanto, disponibilizou-se um número de telefone do professor responsável dessa pesquisa, para que os mesmos pudessem requerer que seus resultados fossem excluídos das análises, se esse desejo se apresentasse. Com a concordância verbal acordada pediu-se que os atletas assinassem o Termo de Consentimento Livre e Esclarecido (TCLE). Somente após essas importantes formalidades iniciou-se a investigaçáo. A aplicação do instrumento de pesquisa foi realizada em uma sala especial nos locais de competiçáo, nos momentos em que os atletas julgassem mais pertinentes, que por solicitação dos próprios atletas aconteceram no contra turno do horário programado para os jogos.

\section{Sujeitos}

A partir das observaçôes de MAguire e Rogers ${ }^{29}$, no que concerne a dificuldade de constituiçáo amostral de base aleatória para estudos em psicologia e educação, a escolha da amostra para esse estudo foi presente estudo busca encontrar evidências que permitam discutir duas questōes: Se há diferenças nos escores médios obtidos entre as três dimensóes da competitividade que compóem a medida da EBMCE-18, independentemente do sexo dos atletas juvenis federados praticantes do "Squash"? E se há diferenças nos escores médios obtidos nas três dimensôes da competitividade que compóem a medida da EBMCE-18, quando controlada a variável "Sexo" dos atletas juvenis federados praticantes do "Squash"?

por conveniência, ou seja, de natureza não aleatória. Sendo assim, essa foi composta, inicialmente, por 36 atletas juvenis de "squash", de ambos os sexos $(\mathrm{M}=18 ; \mathrm{F}=18)$ que participam regularmente de competiçóes oficiais do calendário esportivo de federaçôes regionais e/ou nacionais. Entretanto, um desses atletas respondeu o mesmo valor para todos os itens do instrumento, podendo-se interpretar que ele não entendeu a atividade requerida $\mathrm{e}$, possivelmente, não se sentiu a vontade para perguntar e tirar suas dúvidas. Além disso, devido a essa falta de variabilidade de respostas, decidiu-se retirar esse caso da amostra final, portanto, considerou-se 35 atletas $(\mathrm{M}=17 ; \mathrm{F}=18)$, com idades entre 13 e 18 anos $(16,32 \pm 1,28)$.

\section{Instrumentos}

Nessa pesquisa foram utilizados dois instrumentos: o Questionário de Identificação de Variáveis de Controle (QIVC) ${ }^{6}$, sendo esse apenas para controle das variáveis "Sexo" (masculino ou feminino) e "Idade" (expressa em anos), e a Escala Balbinotti de Motivos à Competividade no Esporte (EBMCE-18). Essa última foi elaborada por BALBinotTI ${ }^{18}$ com o objetivo de se poder conhecer melhor a estrutura subjacente ou intrínseca do construto "Competitividade", quando ligada aos níveis de motivação de praticantes regulares de atividades fisicas ou esportivas (PRAFE). Essa escala possui 18 questôes formuladas positivamente. O somatório das respostas a estas questóes indicam o nível da variável (ou construto) Competitividade em jovens e adultos PRAFE para cada uma das três dimensóes conceitualmente postuladas: Orientação à Vitória $(\mathrm{OV})$, Orientaçáo à Performance (OP) e Orientaçáo ao Status (OS) (ver QUADRO 1). 
Para avaliar os comportamentos de resposta desses jovens, com relação à EBMCE-18, utiliza-se uma escala de tipo Likert, graduada em sete pontos, indo de "isso me motiva pouquíssimo a competir" (1) a "isso me motiva muitíssimo a competir" (7). O tempo de aplicação do instrumento varia entre sete e 15 minutos, devido a natureza simples das afirmaçóes, incluindo as explicaçôes iniciais. Um somatório elevado das respostas de " 1 " a "7" a uma ou outra das três orientaçóes indica que o sujeito se motiva mais fortemente por situaçóes competitivas associadas a tal orientação, revelando, por este viés, uma faceta de sua motivação competitiva, em um sentido mais direto, e de sua personalidade, em um sentido mais

\section{Resultados e discussão}

Visando responder adequadamente as questóes centrais dessa pesquisa, procedeu-se à exploração dos escores obtidos pela EBMCE-18 ${ }^{18}$, segundo princípios métricos comumente aceitos na literatura especializada ${ }^{16,30-37}$. Caminho feito segue de forma sucessiva e sistemática, os resultados das análises de aderência à normalidade dos dados, das análises dos itens, das estatísticas descritivas gerais e, finalmente, das comparaçóes das médias em estudo.

\section{Análises de aderência à normalidade dos dados}

A normalidade dos dados foi demonstrada por gráficos característicos (ver QUADRO 2) e determinada por quatro viéses importantes para a análise de aderência à normalidade da distribuiçáo dos dados disponíveis ${ }^{37-38}: 1$ ) a proximidade relativa dos resultados (portanto, logicamente equivalentes) explorados por três medidas de tendência central $\left(\overline{\boldsymbol{x}}: \Leftrightarrow \tilde{\boldsymbol{x}}: \Leftrightarrow \mathrm{M}_{\mathrm{o}}\right)$ para cada uma das dimensôes em estudo (quando controladas, ou não, pela variável "Sexo") (ver TABELA 1 e 2 para resultados detalhados); 2) a divisão do resultado do cálculo da assimetria por seu erro padrão dentro dos limites adequados $\left(-2,56 \leq \mathrm{A}_{\mathrm{s}} / \mathrm{EP}_{\mathrm{As}} \leq 2,56\right)$ (ver TABELAS 1 e 2 para resultados detalhados); 3) a divisão do resultado do cálculo da curtose por seu erro padrão dentro dos limites adequados $(-2,56 \leq$ $\mathrm{C} / \mathrm{EP}_{\mathrm{C}} \leq 2,56$ ) (ver TABELA 1 e 2 para resultados detalhados); e, finalmente, 4) os resultados de significância do teste Kolmogorov-Smirnov ( $\mathrm{p}$ > 0,05 ), para amostras superiores a 30 casos, quando amplo. Uma recente publicação ${ }^{6}$ demonstrou diversos índices que confirmam a adequabilidade relativa à sua validade de construto, pelos viéses das análises fatoriais exploratórias (saturando em três fatores puros que avaliam as três dimensóes teoricamente postuladas e que explicam cerca de $54 \%$ da variância total do construto) e confirmatórias (GFI = 0,928; AGFI $\left.=0,937 ; \chi^{2} / \mathrm{gl}=1,29 ; \mathrm{RMS}=0,053\right) ; \mathrm{e}$, também, a sua consistência interna, pelos viéses dos cálculos alfa de Cronbach $(0,79<\alpha<0,91)$, dos coeficientes Spearman-Brown corrigido $(0,83<\mathrm{S}-\mathrm{BC}<0,91)$ e do ponto bisserial de Guttman $(0,84<\varphi<0,91)$. Sendo assim, e considerando esses viéses, trata-se de um instrumento válido e fidedigno para uso no Brasil.

corrigido pela técnica de Lilliefors, e do teste ShipiroWilk ( $p>0,05)$, para amostras inferiores a 30 casos por dimensão em análise (ver TABELAS 1 e 2 para resultados detalhados).

Conforme as disposiçóes gráficas apresentadas no QUADRO 2 (curvas semelhantes à uma distribuição normal; pontos observados muito próximos da reta dos valores esperados; e, finalmente, a ausência de casos aberrantes) e os resultados apresentados nas TABELAS 1 e 2, nota-se que não existem problemas importantes ou mesmo significativos $(p<0,05)$ de aderência à normalidade nos dados pesquisados. $\mathrm{O}$ conjunto desses resultados garante o uso de instrumentais paramétricos de medida e de análise dos dados.

\section{Análise dos itens}

Destaca-se que as médias encontradas para cada um dos 18 itens, quando estudados isoladamente, variaram entre 2,33 e 5,75; com desvios-padrão associados variando entre 0,75 a 2,37. Esses resultados indicam que não houve tendência negativa ou positiva de comportamento de resposta da motivação competitiva dos squashistas juvenis testados. Portanto, interpretam-se esses resultados preliminares como sendo satisfatórios, pois não houve aderência predominante a nenhum dos itens isolados, ou seja, itens com médias muito próximas ou semelhantes aos valores extremos ( 1 ou 7 ), o que poderia indicar ausência de variabilidade de respostas no item em questão - condição que poderia impedir o prosseguimento das análises. Destaca-se, então, que as variâncias obtidas $\left(0,56 \leq s^{2} \leq 5,62\right)$ indicam uma 
adequada homogeneidade na dispersão avaliada para cada um dos itens, isoladamente.

Já a média encontrada para o instrumento total (somatório dos 18 itens) foi de 79,25 com um desvio-padrão associado de 16,68. Posto que o intervalo total esperado era de 18 a 126 pontos (com média esperada de 72 pontos) e o observado foi de 53 a 101 (com um intervalo interquartil de 28,75 pontos), observam-se valores relativamente próximos entre as médias esperada e observada. Um teste t para uma amostra permitiu concluir que essa diferença nas médias $\left(D_{\bar{x}}=7,25\right)$ não é estatisticamente significativa $\left(\mathrm{t}_{(34)}=1,505 ; \mathrm{p}=0,161\right)$. Mesmo que a média calculada das correlaçóes item-total $\left(\bar{x}_{r}\right.$ $=0,27)$ possa ser interpretada como satisfatória, pois não indica problemas gerais associados à bicolinearidade dos dados em análise ${ }^{39}, 25$ correlaçóes (das 162) revelaram valores inferiores a $r=0,10$. Estes últimos dados poderiam indicar certa necessidade de revisão das qualidades métricas destes itens, quando considerados isoladamente. Entretanto, comparando-se os índices Alpha, que variaram de 0,85 a 0,88 , para os itens retirados, com o coeficiente Alpha para a escala total $(0,88)$, sem a exclusão de nenhum item, verificou-se que esse procedimento torna-se desnecessário e improdutivo, podendo, inclusive, causar perda na validade de conteúdo ${ }^{40}$, principalmente quanto à pertinência e a adequada exploração de todas as arestas - significados - do conceito em questão.

QUADRO 2 - Demonstração gráfica da aderência à normalidade dos dados em estudo.

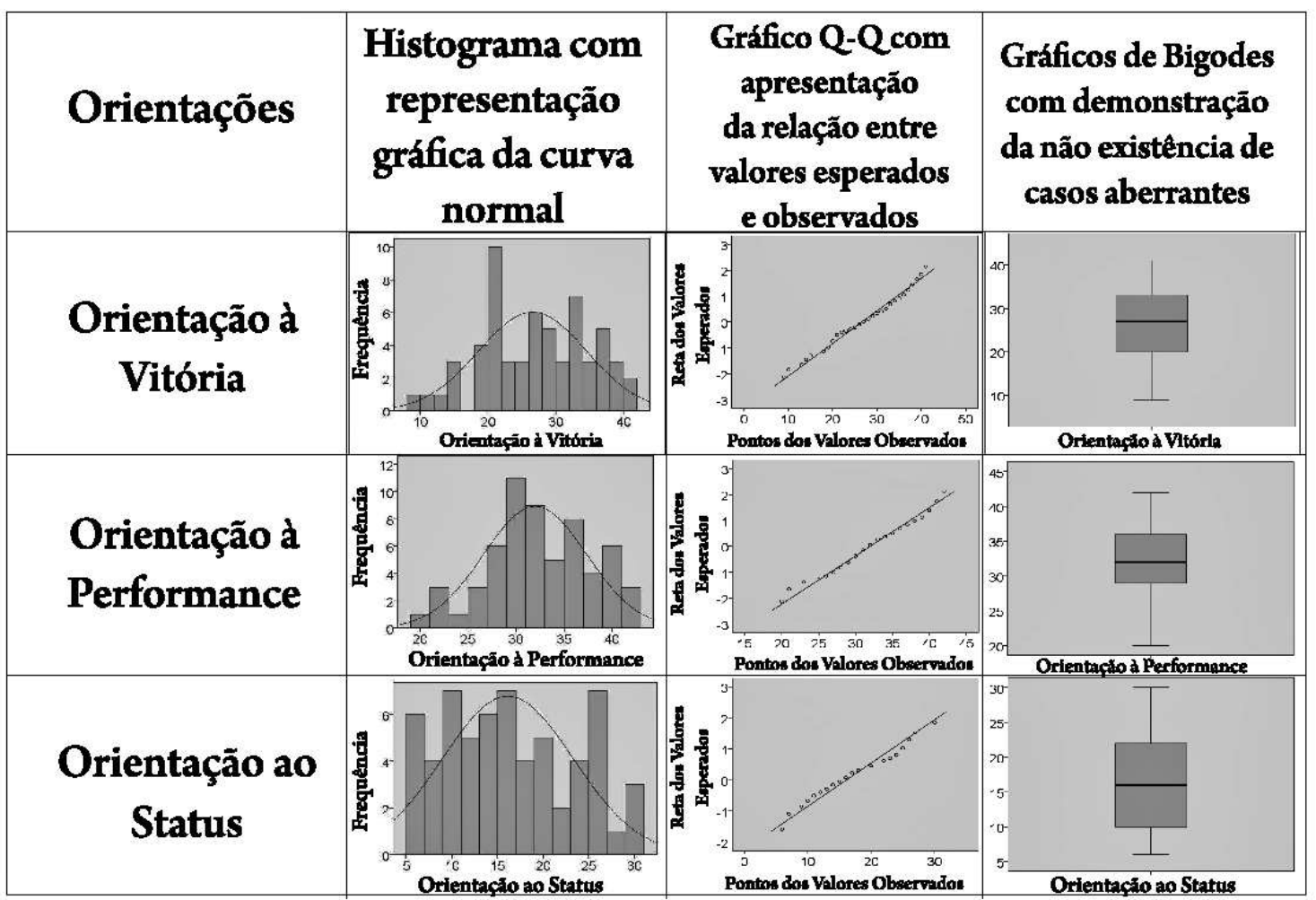

\section{Estatísticas descritivas gerais}

As TABELAS 1 e 2 apresentam resultados de diversas estatísticas descritivas. O primeiro aspecto que vale a pena ser destacado é que as médias calculadas parecem representar adequadamente as respostas gerais dos atletas testados, pois os resultados dos desvios-padrão não ultrapassam a metade dos valores numerais das médias. No mais, pode-se destacar que os resultados médios encontrados para a dimensão OP são os mais elevados, independentemente de ter sido ou náo controlada a variável "Sexo" (ver TABELA 1). Parece que os atletas juvenis testados apresentam uma maior média de motivaçáo competitiva como forma de manifestação dos aspectos relacionados ao desenvolvimento de 
suas próprias habilidades pessoais. Tais resultados vão ao encontro das observaçóes de $\mathrm{JUCHEM}^{24}$ e de BALBinotTi et al. ${ }^{2}$ quando supóem que outros tipos de competitividade poderiam estar influenciando na diminuição significativa dos resultados dessa variável com o avanço das idades. Possivelmente, a OV diminua na mesma proporção que a $\mathrm{OP}$ aumenta de intensidade.

Outro aspecto interessante que a análise dessas tabelas nos permite levantar é que os atletas testados, independente de ter sido ou náo controlada a variável "Sexo", apresentam médias bem inferiores na OS, indicando que eles não competem nesse esporte visando, de maneira fundamental, ascender socialmente. Pode-se dizer que essa realidade não é a mesma de outros esportes, como por exemplo, o Futebol. Benites et al. ${ }^{41}$, em suas reflexóes a respeito da carreira de futebolista profissional, indicam que a busca pelo profissionalismo decorre, precisamente, da apreciação e do "status" social que esse irá proporcionar, assim como a perspectiva de rentabilidade financeira. E essa conclusão não é única desses autores, outros ${ }^{42-43}$ compartilham dessa mesma opinião.

A fim de explorar se essas médias são significativamente diferentes entre si, comparação estatísticas foram realizadas.

TABELA 1 - Estatísticas de tendência central, de dispersão e de distribuição das orientações das motivações competitivas ( $\mathrm{n}=35$ ), sem o controle da variável "Sexo".

\begin{tabular}{|c|c|c|c|c|c|c|c|c|c|c|c|}
\hline & \multicolumn{11}{|c|}{ Estatísticas descritivas } \\
\hline & \multirow{2}{*}{\multicolumn{3}{|c|}{ Tendência central }} & \multirow{2}{*}{\multicolumn{2}{|c|}{ Dispersão }} & \multicolumn{6}{|c|}{ Distribuiçâo } \\
\hline & & & & & & \multicolumn{2}{|c|}{ Normalidade } & \multicolumn{2}{|c|}{ Assimetria } & \multicolumn{2}{|c|}{ Achatamento } \\
\hline & $\chi^{a}$ & $\chi^{\mathrm{b}}$ & $M_{0} c$ & $s^{d}$ & $\mathrm{M}-\mathrm{M}^{\mathrm{e}}$ & $K-S^{f}$ & $\mathrm{p}$ & As $\mathrm{g}$ & EPAs $^{h}$ & $\mathrm{C}^{\mathrm{i}}$ & $\mathrm{EPC}^{\mathrm{j}}$ \\
\hline OV & 29,42 & 32,0 & 34 & 7,51 & $09-41$ & 0,229 & 0,082 & $|0,17|$ & 0,64 & $|1,65|$ & 1,23 \\
\hline OP & 33,33 & 32,5 & 30 & 4,58 & $20-42$ & 0,184 & 0,466 & $|0,34|$ & 0,64 & $|1,27|$ & 1,23 \\
\hline OS & 16,49 & 15,0 & 16 & 7,45 & $06-30$ & 0,144 & 0,548 & $|0,51|$ & 0,64 & $|0,84|$ & 1,23 \\
\hline
\end{tabular}

TABELA 2 - Estatísticas de tendência central, de dispersão e de distribuição das motivações competitivas (n = 35), controladas pela variável "Sexo".

\begin{tabular}{|c|c|c|c|c|c|c|c|c|c|c|c|}
\hline & \multicolumn{11}{|c|}{ Estatísticas descritivas } \\
\hline & \multirow{2}{*}{\multicolumn{3}{|c|}{ Tendência central }} & \multirow{2}{*}{\multicolumn{2}{|c|}{ Dispersáo }} & \multicolumn{6}{|c|}{ Distribuição } \\
\hline & & & & & & \multicolumn{2}{|c|}{ Normalidade } & \multicolumn{2}{|c|}{ Assimetria } & \multicolumn{2}{|c|}{ Achatamento } \\
\hline & $\chi^{a}$ & $\chi^{b}$ & $M_{o} c$ & $s^{d}$ & $M-M^{e}$ & $K-S^{f}$ & $\mathrm{p}$ & As ${ }^{g}$ & EPAs ${ }^{h}$ & $\mathrm{C}^{\mathrm{i}}$ & $\mathrm{EPC}^{\mathrm{j}}$ \\
\hline $\mathrm{OV}_{\mathrm{M}}$ & 31,21 & 34 & 24 & 6,10 & $09-40$ & 0,848 & 0,190 & $|1,04|$ & 0,91 & $|0,42|$ & 2,01 \\
\hline $\mathrm{OV}_{\mathrm{F}}$ & 28,14 & 30 & 26 & 8,61 & $10-41$ & 0,847 & 0,119 & $|0,13|$ & 0,79 & $|2,44|$ & 1,59 \\
\hline $\mathrm{OP}_{\mathrm{M}}$ & 34,01 & 32 & 32 & 4,85 & $20-41$ & 0,862 & 0,235 & $|0,86|$ & 0,91 & $|1,19|$ & 2,01 \\
\hline $\mathrm{OP}_{\mathrm{F}}$ & 32,85 & 33 & 33 & 4,71 & $21-42$ & 0,919 & 0,464 & $|0,14|$ & 0,79 & $|1,82|$ & 1,59 \\
\hline $\mathrm{OS}_{\mathrm{M}}$ & 17,01 & 16 & 16 & 6,93 & $07-30$ & 0,920 & 0,529 & $|0,37|$ & 0,91 & $|2,09|$ & 2,01 \\
\hline $\mathrm{OS}_{\mathrm{F}}$ & 16,14 & 16 & 16 & 8,34 & $06-29$ & 0,950 & 0,732 & $|0,72|$ & 0,79 & $|0,28|$ & 1,59 \\
\hline
\end{tabular}

a = Média;

$\mathrm{b}=$ Mediana;

${ }^{\mathrm{c}}=$ Moda;

${ }^{\mathrm{d}}=$ Desvio-Padrão;

e= Minimo-Máximo;

$\mathrm{f}=$ Kolmogorov-Smirnov;

$9=$ Assimetria;

$\mathrm{h}=$ Erro-Padrão da Assimetria;

$i=$ Curtose;

j= Erro-Padrão da Cur-

tose.

\section{Comparações das médias}

Para que se possa responder adequadamente a primeira questáo central dessa pesquisa (há diferenças significativas nos escores médios obtidos entre as três dimensôes da competitividade, independentemente do sexo dos atletas juvenis federados praticantes do "Squash"?), conduziu-se uma ANOVA de fator único para medidas repetidas ${ }^{44}$, sendo que o fator geral e único é a "competitividade" e as variáveis dependentes são os escores nas três orientaçôes medidas. Teve-se, ainda, o cuidado de explorar dois outros importantes pré-requisitos (além daqueles referentes à aderência à normalidade da distribuição) para a utilização e interpretação adequada dessa análise: 1) testou-se a hipótese da matriz de covariância residual ser estatisticamente igual à matriz de identidade com ajuda do teste de esfericidade de $\operatorname{Bartlett}\left(\chi_{B}^{2}=13,91\right.$; 
$\mathrm{p}<0,05) ; 2)$ testou-se a hipótese das diferenças dos escores serem normalmente distribuidas $(1,58 \leq \mathrm{K}-\mathrm{S}$ $\leq 2,09 ; \mathrm{p}>0,05)$ e afirma-se que a diferença dos escores é independente para cada indivíduo, pois não existem testes com resultados iguais. Tendo em vista esses cuidados nos procedimentos, conduziram-se as análises em três etapas: 1) efetuou-se uma análise de variância para se determinar se existe, ao menos, uma diferença estatisticamente significativa entre as médias calculadas; 2) efetuou-se uma série de comparaçóes pareadas das diferenças calculadas para se determinar, precisamente, quais os pares de médias que se diferenciam estatisticamente; e, finalmente, 3) efetuou-se uma análise de contrastes polinomiais para se determinar se há um efeito linear significativo entre as médias das orientações em estudo.

Os resultados da primeira etapa dessa análise, pelos viéses dos testes Lambda de Wilk $\left(\mathrm{W}_{\Lambda}=0,089\right)$, Trace de Pillai $\left(\mathrm{P}_{\Gamma}=0,911\right)$ e de Hotelling $\left(\mathrm{H}_{\Gamma}=\right.$ $10,295)$, e o teste da Raiz de Roy $\left(R_{\Sigma}=10,295\right)$, indicaram um efeito significativo $\left(\mathrm{F}_{(2,33)}=51,473\right.$; $\mathrm{p}$ $\left.<0,001 ; \eta_{\mathrm{p}}{ }^{2}=0,911\right)$ entre as médias das orientaçóes calculadas. Mas para que se possa saber entre qual (ou quais) par (ou pares) de médias, efetuou-se uma segunda etapa, ou seja, uma série de testes t para amostras pareadas. Dos três pares testados, conforme apresentado na TABELA 3, o único par que não se deferencia significativamente é o primeiro, aquele entre as orientaçóes à vitória e à performance. Pois, após a correção do nível de significância $(\alpha=0,05$ \% $3=0,0167$ ) em função do número de comparaçóes efetuadas, conforme o procedimento sequencial de Bonferroni, adaptado por $\mathrm{Holm}^{39}$ - que tem objetivo diminuir a probabilidade de incidência do Erro Tipo I (assumir como estatisticamente significativa uma diferença que, na realidade, não o é) - não se pode assumir essa diferença como estatisticamente significativa sem correr o risco de incorrer no Erro Tipo I. Mas, destaca-se que o nível de significância encontrado $(0,047)$ é relativamente próximo ao limite de significância assumido $(\mathrm{p}<0,0167)$ e, portanto, sugere-se que novos estudos, com amostras maiores, possam explorar novamente essas diferenças com o intuito de se tomar conhecimento se esse nível de significância encontrado sofreu uma possível influência das condiçóes amostrais desse estudo.

TABELA 3 - Estatísticas descritivas das diferenças e comparações entre as médias ( $\mathrm{n}=35$ ), não controladas pela variável "Sexo".

\begin{tabular}{|c|c|c|c|c|c|c|}
\hline \multirow{2}{*}{ Pares } & \multirow{2}{*}{$\begin{array}{l}\text { Comparaçóes } \\
\text { pareadas }\end{array}$} & \multicolumn{2}{|c|}{$\begin{array}{l}\text { Estatísticas descritivas das } \\
\text { diferenças entre as médias }\end{array}$} & \multicolumn{3}{|c|}{ Teste $t$ para amostras pareadas } \\
\hline & & $\mathbf{D} \overline{\mathbf{x}}$ & Ds & $\mathbf{t}$ & gl & $\mathbf{p}<$ \\
\hline Par 1 & OV vs. OP & $|3,92|$ & 6,96 & 1,949 & 34 & 0,047 \\
\hline Par 2 & OV vs. OS & $|12,92|$ & 5,02 & 8,918 & 34 & 0,001 \\
\hline Par 3 & OP vs. OS & $|16,83|$ & 6,85 & 8,517 & 34 & 0,001 \\
\hline
\end{tabular}

A terceira etapa dessa mesma análise, a etapa dos contrastes polinomiais para medidas repetidas pelo viés do teste $L$ de constrastes intra-sujeitos de Levene, apresentou resultados $\left(\mathrm{F}_{\mathrm{L}(1,34)}=79,529 ; \mathrm{p}<\right.$ 0,$\left.01 ; \eta_{\mathrm{p}}{ }^{2}=0,878\right)$ que podem ser interpretados de forma positiva, no sentido de indicarem a existência de um aumento linear estatisticamente significativo $(\mathrm{p}<0,05)$ de intensidade de motivação competitiva desses atletas, partindo da orientaçáo ao "status" (índice menos elevado) para chegar à orientação à performance (índice mais elevado). Deve-se destacar mais uma vez que a diferença das médias entre as orientações OV e OP não é estatisticamente significativa (ver TABELA 3), portanto é necessário levar esse aspecto em consideração.

Esse conjunto de resultados, principalmente aqueles que respondem mais diretamente a primeira questão dessa pesquisa, corroboram, ao menos em parte, com as observaçóes de RobBins ${ }^{45}$ e BowDITCH ${ }^{46}$, quando afirmam que as orientaçóes competitivas (vitória, performance e "status" social) estáo relacionadas às noçóes de poder, no sentido de excercer influência sobre outras pessoas, uma das dimensóes postuladas pela Teoria des Necessidades Socialmente Adquiridas (TNSA), elaborada por MCClelland $^{47}$. Nesse sentido, pode-se interpretar que os "Squashistas" testados manifestam suas motivaçôes competitivas pelo viés do "poder", querendo expressá-lo via submissão do outro, ou seja, visando melhorar suas performances para ganhar dos outros. Isso se dá de maneira estatisticamente indissociável. Assim, a melhora na performance e a vitória sobre os outros são manifestaçóes de poder significativamente mais motivadoras que a obtenção de um "status" social e reconhecimento financeiro, ao menos nessa categoria (Juvenis) e nesse esporte 
(“Squash”), em estudo. De acordo com Marques ${ }^{48}$, a orientação à performance e à vitória é normalmente mais incidente em relação a orientação ao status, pois principalmente "a vitória é uma natural aspiração dos jovens desportistas" (p.82).

Para que se possa responder adequadamente a segunda questáo central dessa pesquisa (há diferenças significativas nos escores médios obtidos entre as três dimensóes da competitividade, quando controlada a variável "Sexo" dos atletas juvenis federados praticantes do "Squash"?) conduziu-se uma ANOVA de um caminho para medidas independentes ${ }^{44}$. Teve-se, ainda, o cuidado de explorar outro importante prérequisito (que não fora testado anteriormente) para a utilização e interpretação adequada dessa análise: 1) testou-se a hipótese da homogeneidade da variância para os três grupos de orientaçóes competitivas pelo viés do teste $F$ de Levene e seus resultados $\left(F_{\mathrm{OV}(1,33)}=\right.$ 2,$738 ; \mathrm{p}>0,05 ; F_{\mathrm{OP}(1,33)}=0,011 ; \mathrm{p}>0,05 ; F_{\mathrm{OS}(1,33)}$ $=0,131 ; \mathrm{p}>0,05)$ não deixam dúvidas: tratam-se de orientaçôes com variâncias homogênias. Sendo assim, e considerando a adequabilidade dos outros prérequisitos já testados, pode-se interpretar os resultados dessa última análise realizada $\left(F_{\mathrm{OV}(1,33)}=0,459 ; \mathrm{p}>\right.$ 0,$05 ; F_{\mathrm{OP}(1,33)}=0,168 ; \mathrm{p}>0,05 ; F_{\mathrm{OS}(1,33)}=0,035$; $\mathrm{p}>0,05)$, diga-se, não há diferenças significativas entre as médias das orientaçóes, quando controladas pela variável "Sexo". Esses resultados nos permitem concluir que o fato de pertencer ao sexo masculino ou feminino não influencia a expressão da motivação competitiva, ao menos aquelas medidas pela EBMCE-18, e independente da orientação em análise.

Esse conjunto de resultados, principalmente aqueles que respondem mais diretamente a segunda questão dessa pesquisa, corroboram, ao menos em parte, com as observaçóes de OliveIra ${ }^{49}$ a respeito das competiçôes, as diferenças dos sexos e os hormônios. Mais precisamente, conforme essa autora, não se pode falar de motivação competitiva, em atletas homens e mulheres, sem falar de hormônios. Essa autora afirma que, no caso dos homens, já é sabido que os níveis de testosterona aumentam por antecipação a uma competição esportiva, mantendo-se elevados nos vencedores e decrescendo para níveis basais nos derrotados. Com base nessas observaçōes, essa autora pesquisou, entre outros aspectos, os níveis de testosterona de jogadoras de duas equipes de futebol feminino, que disputariam a final do Campeonato Nacional de Futebol Feminino Português. Os resultados não foram diferentes, houve um aumento significativo maior nos níveis de testosterona pré e durante o jogo, contrariamente aos da equipe derrotada que sofreram um decréscimo significativo após os jogos. Sendo assim, a autora conclui que, de forma geral, esses (e outros) resultados demonstram que há uma resposta psicofisiológica semelhante entre homens e mulheres em situaçáo de competição, portanto, não existe uma razão cabal que justifique diferenças significativas entre os sexos quando testados os níveis de motivação competitiva e suas orientaçōes intrínsecas.

A Motivação Competitiva (MC), ou simplesmente competitividade, e o esporte tem sido entendido como conceitos completamente interligados, até mesmo indissociáveis. Portanto, parece de fundamental importância explorar/utilizar um instrumento especificamente construído para a sua medida. Esse estudo teve por objetivo central (pelo viés das minuciosas respostas às duas questóes centrais), explorar e comparar o perfil motivacional competitivo de 35 "squashistas" juvenis federados, de ambos os sexos e com idades entre 13 e 18 anos; que, para tanto, responderam a Escala Balbinotti de Motivos à Competividade no Esporte (EBMCE-18), que avalia três orientaçóes distintas e intrínsecas da motivação competitiva: Orientação à Vitória (OV), Orientação à Performance $(\mathrm{OP})$ e Orientaçao ao Status (OS). A MC é uma característica da personalidade humana, que pode ser tipicamente encontrada em atletas, mas, é claro, que náo unicamente. A psicologia do esporte, pelo viés da psicometria, é particularmente interessada em entender as dimensôes intrínsecas dos aspectos da personalidade humana, principalmente aqueles ligados ao esporte. Sendo assim, pode-se dizer que a competitividade é uma característica que pode interessar a várias ciências, particularmente, as do movimento humano e as psicológicas.

Os resultados encontrados permitem dizer que, no caso do "Squash", a competitividade pode estar associada às importantes características típicas desse esporte: habilidades técnicas e velocidade de ação decisional e de movimentos, através da execução alternada de açóes táticas. Sendo assim, não se deve interpretar essa característica de personalidade como se ela fosse de natureza unidimensional. Dizer que um atleta é simplesmente "bastante competitivo" (ou "pouco competitivo"), pode-se estar reduzindo a qualidade dessa interpretação, ou seja, pode-se estar perdendo as nuances importantes e intrínsecas à competitividade. A partir dos resultados desse estudo, parece que é mais adequado interpretar qual o tipo de MC, ou qual o perfil de MC, que é mais característico desse atleta, ou mesmo de 
uma determinada categoria de atletas, que no caso do "squash" poderia ser dividida em atletas "Juvenis", "Adultos", "Profissionais" e "Masters". Dessa forma, e com base nos resultados observados das médias gerais (sem o controle da variável "Sexo"), os "Squashistas" juvenis federados testados nessa pesquisa se caracterizam como atletas que visam, inicialmente, melhorar suas performances gerais (suas habilidades, suas velocidades, suas açôes táticas), para, quem sabe, num determinado momento futuro (recente ou não), se perceberem melhores que os outros e visarem, em um segundo momento, mais fundamentalmente ganhar competiçóes. Mas, destaca-se que, essa observação é baseada apenas nos valores médios obtidos, pois não se pode fazer essa afirmação quando se considera unicamente as probabilidades estatísticas calculadas; embora náo se possa deixar de salientar que o nível de significância encontrado não se afasta enormemente do limite inicialmente determinado. Portanto, deve-se interpretar que essa pequena diferença pode ter sido influenciada (em maior ou menor grau) pela amostra em questáo. E nesse sentido, novos estudos devem ser conduzidos para esclarecer melhor essa situação, pois, em última análise, as médias foram, em termos numerais, maiores para a dimensão OP. Outra possível conclusão decorrente desses mesmos resultados indica que os atletas pesquisados queiram realmente melhorar suas performances gerais, mas com a mesma forma e intensidade estatística. Além disso, é possível que eles também queiram ganhar dos outros competidores, afinal como indica $\mathrm{MA}_{\mathrm{A}}$ TVEEV $^{19}$, o objetivo do atleta deve ser o de alcançar o máximo em termos individuais para superar os outros. E nesse sentido, essas duas valências podem ser efetivamente indiferenciadas, ao menos para esse esporte e para essa categoria. Assim, outros estudos, com outros esportes (considerando as diversas categorias), poderão esclarecer melhor esse ponto; pois conforme as observaçóes de Weinberg e Gould ${ }^{15}$ e das conclusóes de BalbinotTi et al. ${ }^{6}$, trata-se de dois aspectos intrínsecos e independentes da competitividade. Finalmente, conclui-se que o fato de pertencer a um ou outro dos sexos não influencia a manifestaçáo de resposta à EBMCE-18. Isso, com relação a qualquer das três orientaçôes avaliadas.

A maior limitação dessa pesquisa seja a não possibilidade de generalização dos resultados obtidos; afinal de contas, os dados foram coletados com base em procedimentos não aleatórios para a composição da amostra. Novos estudos com diferentes amostras, de diferentes esportes e de diferentes categorias, devem ser conduzidos para que se possa aprofundar mais as nuances importantes relacionadas à $\mathrm{MC}$ e sua medida.

\begin{abstract}
The competitive motivation of youth federated squash players: an exploratory and comparative study

The Competitive Motivation (MC) is a fundamental personality trait in the context of sports. Recently, a new model for assessing the MC called Three-dimensional Model of Competitive Motivation Assessment (TMCMA) was proposed. This model assumes that the MC has three distinct competitive orientations: to win (OV), to perform (OP), and to obtain status (OS). The purpose of this research is to explore and compare the competitive motivational profile of 35 youth federated squash players, of both genders, and aged between 13 to 18 years old. Therefore, this sample answered to the Balbinotti's Scale of Competitive Motivation in Sport (BSCMS-18). The two main results were: 1) the orientations emerged as OP, OV, and $\mathrm{OS}$, in this order, being $\mathrm{OP}$ and $\mathrm{OV}$ the only one of three analyzed pairs that is statistically nonsignificant; 2) the gender variable does not significantly influence the intensity of the answers in any of the three orientations tested. Further studies should explore whether the statistically non-significant mean difference found between OP and OV was influenced by the sample size.
\end{abstract}

KeY woRds: Competitiveness; Squash; Motivation; Psychometrics. 


\section{Referências}

1. Balbinotti AAM. Inventário de motivaçấo a pratica regular de atividade física (IMPRAFE-126): 2a versão. Porto Alegre: Laboratório de Psicologia do Esporte, Universidade Federal do Rio Grande do Sul; 2004.

2. Balbinotti MAA, Saldanha RP, Balbinotti CAA. Dimensóes motivacionais de basquetebolistas infanto-juvenis: um estudo segundo o sexo. Motriz. 2009;15:318-29.

3. Barbosa MLL, Balbinotti CAA, Gonzalez RH, Balbinotti MAA, Ferreira AO. A motivação à prática de atividade física regular relacionada à competitividade em adolescentes do sexo feminino. Coleç Pesqui Educ Fís. 2008;7:109-14.

4. Gonzalez RH, Barbosa LL, Balbinotti CAA, Ferreira AO, Balbinotti MAA. A motivação à prática de atividade física regular relacionada à Competitividade em adolescentes do sexo masculino. Coleç Pesqui Educ Fís. 2008;7:59-66.

5. Balbinotti MAA, Balbinotti CAA. Motivação e perspectiva futura no tênis infanto-juvenil. Rev Bras Psicol Esporte. 2008;2:1-20.

6. Balbinotti MAA, Barbosa MLL, Saldanha RP, Balbinotti CAA. Estudos fatoriais e de consistência interna da escala Balbinotti de motivos à competitividade no esporte. Motriz. 2011;17:318-27.

7. Marques AT, Oliveira JM. O treino dos jovens desportistas: atualização de alguns temas que fazem a agenda do debate sobre a preparação dos mais jovens. Rev Port Ci Desporto. 2001;1:130-7.

8. Truby Junior O. The science and strategy of squash. New York: Congress Cataloging; 1975.

9. Robinson I. Skilful squash. London: A \& C Black; 1990.

10. Moreno JH. Fundamentos del deporte: análisis de las estructuras del juego deportivo. Barcelona: INDE; 2005.

11. Squash Rackets Association. Know the game. London: A \& C Black; 1995.

12. Beddington J. Squash: técnica y tácticas. Barcelona: Hispano Europea; 1986.

13. Bompa TO. Periodização: teoria e metodologia do treinamento. São Paulo: Phorte; 2002.

14. Aburachid LMC, Soares VOV, Greco PJ. Análise das açôes técnicas e finalizaçóes no torneio dos campeóes profissionais de squash em Nova York, 2005. Lect Educ Fís Deportes. 2009;14. Disponible em: http://www.efdeportes.com/ efd136/analise-das-acoes-tecnicas-em-squash.htm.

15. Weinberg R, Gould D. Fundamentos da psicologia do esporte e do exercício. 2a ed. Porto Alegre: Artmed; 2006.

16. Dassa C. Analyse multidimensionnelle exploratorie et confirmative. Montréal: Université Montréa; 1999.

17. De Rose D, Korsakas P. O processo de competição e o ensino do desporto. In: Tani G, Bento JO, Petersen RD, organizadores. Pedagogia do desporto. Rio de Janeiro: Guanabara Koogan; 2006. p.251-61.

18. Balbinotti MAA. Inventário de motivos para a prática regular de atividades físicas e esportivas (IMPRAF-132): $3^{\mathrm{a}}$ versão. Montréal: Service d'Intervention et de Recherche en Orientation et Psychologie; 2010.

19. Matveev LP. Teoría general del entrenamiento deportivo. Barcelona: Paidotribo; 2001.

20. Martens R, Velley R, Burton D. Competitive anxiety in sport. New York: Human Kinetics; 1990.

21. De Rose Junior D. Esporte, competição e estresse: implicaçôes na infância e na adolescência. In: De Rose Junior D, organizador. Esporte e atividade física na infância e na adolescência. Porto Alegre: Artmed; 2009. p.103-14.

22. Proni MW. Esporte-espetáculo e futebol-empresa [tese]. Campinas (SP): Universidade Estadual de Campinas, Faculdade de Educação Física; 1998.

23. Barbosa MLL. Propriedades métricas do inventário de motivação à prática regular de atividades físicas [dissertação]. Porto Alegre (RS): Universidade Federal do Rio Grande do Sul, Escola de Educação Física; 2006.

24. Juchem L. Motivaçáo à prática regular de atividades físicas: um estudo sobre tenistas brasileiros infanto-juvenis. [dissertação]. Porto Alegre (RS): Universidade Federal do Rio Grande do Sul, Escola de Educação Física; 2006.

25. Balbinotti MAA, Capozzoli CJ. Motivação à prática regular de atividade física: um estudo exploratório com praticantes em academias de ginástica. Rev Bras Educ Fís Esporte. 2008;22:63-80.

26. Cohane G, Pope Junior H. Body image in boys: a review of the literature. Int J Eat Disord. 2001;29:373-9.

27. Robertson J, Mutrie N. Factors in adherence to exercise. Phys Educ Rev. 1989;12:138-46.

28. Lores A, Murcia J, Sanmartín M, Camacho Á. Motivos de práctica físico-desportiva según la edad y el género en una muestra de universitarios. Apunts. 2004;76:13-21.

29. Maguire T, Rogers W. Proposed solutions for non randomness in educational research. Can J Educ. 1989;14:170-81.

30. Bisquera R. Introducción a la estadística aplicada a la investigación educativa: un enfoque informático con los paquetes BMDP y SPSS. Barcelona: PPU; 1987.

31. Vallerand M. Ver une métodologie de validation transculturelle des questionnaires psychologiques: implications pour la recherche em langue française. Can Psychol. 1989;30:662-80. 
32. Trudel R, Antonius R. Méthodes quantitatives appliquées aux sciences humainess. Montréal: Les Éditions de la Cheneliére; 1991.

33. Angers M. Initiation pratique à la méthodologie des sciences humaines. Montréal: Les Editions de La Chenelière; 1992.

34. Bryman A, Cramer D. Quantitative data analysis with SPSS release 8 for Windows: a guide for social scientists. New York: Routledge; 1999.

35. Sirkin RM. Statistics for the social sciences. London: Sage; 1999.

36. Reis E. Estatística descritiva. Lisboa: Sílabo; 2000.

37. Pestana MH, Gageiro JG. Análise de dados para ciências sociais: a complementaridade do SPSS. Lisboa: Sílabo; 2003.

38. Field A. Descobrindo a estatística utilizando o SPSS. 2a ed. São Paulo: Artmed; 2009.

39. Tabachnick B, Fidell L. Using multivariate statistics. 6th ed. Portland: Green Earth; 2012.

40. Balbinotti MAA. Para se avaliar o que se espera: reflexóes a cerca da validade dos testes psicológicos. Rev Aletheia. 2005;21:43-52.

41. Benites LC, Barbieri FA, Souza Neto S. O futebol: questões e reflexões a respeito dessa profissão. Pensar Prát. 2007; 10:51-67.

42. Lawson H. Invitation to physical education. Champaign: Human Kinetics; 1984.

43. Sebreli J. La era del fútbol. Buenos Aires: Debolsillo; 2005.

44. Green S, Salking N. Using SPSS for Windows and Macintosh: Analyzing and understanding data. 5th ed. New York: Pearson International; 2008.

45. Robbins SP. Motivação no trabalho e recompensas. In: Robbins S. Administração: mudanças e perspectivas. São Paulo: Saraiva; 2002. p.35-47.

46. Bowditch JL. Motivação. In: Bowditch JL. Elementos do comportamento organizacional. São Paulo: Pioneira; 1992. p.39-61.

47. McClelland DC. Toward a theory of motive aqquisition. Am Psychol. 1965;20:321-33.

48. Marques AT. Fazer da competição dos mais jovens um modelo de educação e formação. In: Gaya A, Marques AT, Tani G, organizadores. Desporto para crianças e jovens: razóes e finalidades. Porto Alegre: Editora da UFRGS; 2004. p.75-96.

49. Oliveira TSF. A testosterona e a competição em mulheres [dissertação]. Lisboa (PT): Universidade de Lisboa, Instituto Superior de Psicologia Aplicada; 2005.

\begin{tabular}{|c|c|}
\hline $\begin{array}{r}\text { ENDEREÇO } \\
\text { Fernando Machado Cechin } \\
\text { R. Áustria, 219 } \\
\text { 92022-070 - Canoas - RS - BRASIL } \\
\text { e-mail: fernandocechin@gmail.com }\end{array}$ & $\begin{array}{l}\text { Recebido para publicação: 09/04/2012 } \\
\text { 1a. Revisão: 05/11/2012 } \\
\text { 2a. Revisão: 20/06/2013 } \\
\text { Aceito: 09/06/2014 }\end{array}$ \\
\hline
\end{tabular}

